UNIVERSIDADE DE SÃO PAULO

FACULDADE DE ODONTOLOGIA

\title{
ESTUDO “IN VITRO” DA LISURA DA SUPERFÍCIE DAS \\ LIGAS DE TITÂNIO E NÍQUEL-CROMO, SUBMETIDAS À CICLAGEM TÉRMICA EM INTERVALOS DE TEMPO, COM A UTILIZAÇÃO DA RUGOSIMETRIA
}

Wilson Tavares de Oliveira Jr.

Tese apresentada à Faculdade de Odontologia da Universidade de São Paulo, para obtenção do Título de Doutor, pelo Curso de Pós-Graduação em Odontologia.

Área de Concentração em Dentística.

São Paulo

2000 
UNIVERSIDADE DE SÃO PAULO

FACULDADE DE ODONTOLOGIA

\section{ESTUDO “IN VITRO” DA LISURA DA SUPERFÍCIE DAS LIGAS DE TITÂNIO E NÍQUEL-CROMO, SUBMETIDAS À CICLAGEM TÉRMICA EM INTERVALOS DE TEMPO, COM A UTILIZAÇÃO DA RUGOSIMETRIA}

Wilson Tavares de Oliveira Jr.

Tese apresentada à Faculdade de Odontologia da Universidade de São Paulo, para obtenção do Título de Doutor, pelo Curso de Pós-Graduação em Odontologia.

Área de Concentração em Dentística.

Orientador:

Prof. Associado Michel Nicolau Youssef

São Paulo 
Aos meus pais Maryte e Wilson, pela dedicação e incentivo em mais este trabalho e em todos os momentos de minha vida.

E também æ̀̀ minhas irmãs Silvia e Flávia, pelo apoio, confiança e consideração depositados em mim. 
Nesta tese, reitero mais uma vez, ao meu orientador, Prof. Dr. Michel Nicolau Youssef, meu sincero agradecimento, pela sua paciência, incentivo, estima e confiança ao longo desses anos. 
Outrossim, tenho de ratificar minha reverência ao Prof. Dr. Dan Mihail Fichman, por seus conselhos, estímulo e amizade. 


\section{AGRADECIMENTOS}

Ao Prof. Dr. Antonio Adamastor Corrêa, ao qual mais uma vez dedico minha admiração, por ter, através de seus conselhos, enriquecido o meu aprendizado.

Ao Prof. Dr. Rubens Corte Real de Carvalho, sempre com o espírito alegre, pela paciência, amizade e inestimável ajuda neste trabalho.

Ao Prof. Dr. Edmir Matson, pela sua compreensão em todos os momentos desta jornada, sendo sempre motivo de minha admiração e, sobretudo, meu respeito.

Ao Prof. Dr. Fernando Luis Brunetti Montenegro, conselheiro, responsável, amigo e por tantas outras virtudes, ao longo deste tempo, meu mais sincero agradecimento.

Ao Prof. Dr. Ruy Fonseca Brunetti, pelo apoio dado ao desenvolvimento da minha carreira. 
À Prof. Dra. Ada Maria Fossen, sempre presente nestes anos de mestrado e doutorado, ratifico meu agradecimento pelo seu apoio.

Ao doutorando Maurício Casa, pela amizade e inestimável ajuda na confecção das microscopias deste trabalho.

Aos colegas da Disciplina de Dentística Operatória e do curso de PósGraduação do Departamento de Dentística e Endodontia da FOUSP, em especial à pós - graduanda Grázia Vivian Esteves e ao pós graduando Ricardo Scarparo Navarro, pela ajuda e compreensão em todos os momentos.

À Sra. Neiva Galindo Corrêa agradeço a amizade, carinho e ajuda em todas as fases pela qual passei nessa Faculdade.

Ao Sr. Arnaldo Pedroza da Silva que esteve sempre firme e disposto a ajudar e cooperar não só neste trabalho, mas em toda a convivência acadêmica.

À Sra. Lúcia Lara pela correção ortográfica deste trabalho, além de sempre poder contar com sua ajuda. 
Ao Laboratório de Prótese Dental Nicolau, na pessoa do Sr. Nicolau Cury e Ildefonso Benedito Gomes, pela considerável cooperação neste trabalho.

A todos meus colegas da Faculdade de Odontologia da Universidade de São Paulo e da Universidade Paulista - UNIP que, de uma forma direta ou indireta, colaboraram para a execução deste trabalho. 


\section{SUMÁRIO}

RESUMO

p.

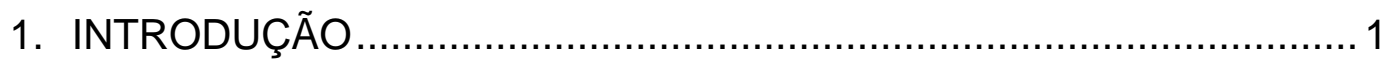

2. REVISÃO DA LITERATURA ............................................... 3

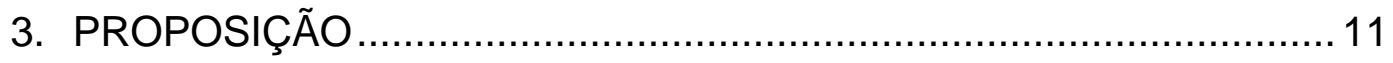

4. MATERIAL E MÉTODOS ................................................ 12

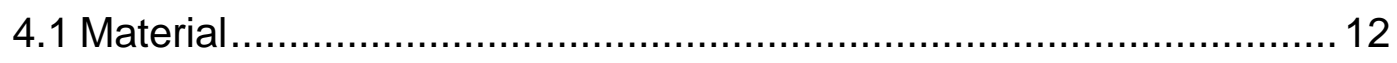

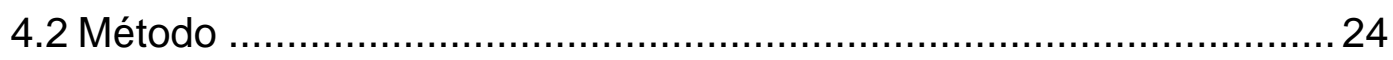

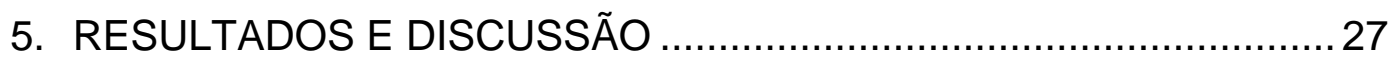

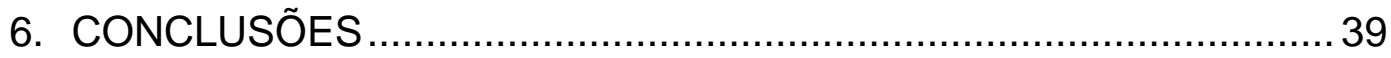

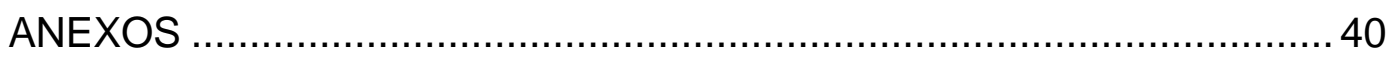

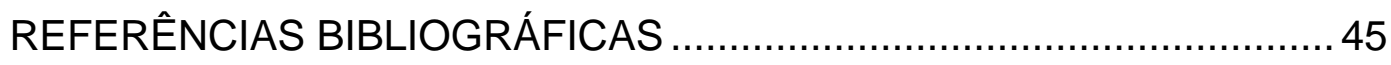

SUMMARY

APÊNDICES 


\section{LISTA DE FIGURAS}

Figura 1 - Apresentação das ligas de Ti e Ni Cr em seu estado comercial...... 13

Figuras 2a e 2b-Revestimentos utilizados para inclusão de Ti e Ni Cr.. 16

Figura 3 - Instrumentos rotatórios utilizados para acabamento e polimento de $\mathrm{Ti}$ 17

Figura 4 - Instrumentos rotatórios utilizados para acabamento e polimento de $\mathrm{Ni} \mathrm{Cr}$ 18

Figura 5 - Material acondicionador dos corpos de prova. 20

Figura 6 - Aparelho de ciclagem térmica marca MCT 2 -AMM Instrumental....21

Figura 7 - Estufa utilizada da marca Hereus * modelo RT 360 22

Figura 8 - Detalhes do aparelho de leitura Surftest 211, série 178, fabricado pela Mitutoyo do Brasil 23

Figura 9 - Dispositivo para padronização das leituras no corpo de prova .26

Figura 10 - Médias em função de Fase e Tipo de Liga 28

Figura 11 - Intervalos de confiança (95\%) para a média das duas ligas nas três fases 29 


\section{LISTA DE TABELAS}

TABELA 4.1 - Descrição das ligas..................................................... 13

TABELA 4.2 - Composição dos metais que compõem as ligas................ 14

TABELA 4.3 - Composição da saliva artificial...................................... 19

TABELA 5.1 - Médias e desvios padrão da rugosidade para cada fase e

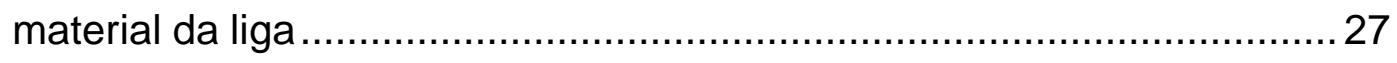

TABELA 5.2 - Resultados da análise de medidas repetidas ...................29 


\section{RESUMO}

\section{ESTUDO “IN VITRO” DA LISURA DA SUPERFÍCIE DAS LIGAS DE TITÂNIO E NÍQUEL-CROMO, SUBMETIDAS À CICLAGEM TÉRMICA EM INTERVALOS DE TEMPO, COM A UTILIZAÇÃO DA RUGOSIMETRIA}

A capacidade de resistência àcorrosão sofrida pelas próteses dentais confeccionadas com ligas metálicas é de grande importância na clínica odontológica devido àocorrência de possíveis reações biológicas, como por exemplo, sintomas alérgicos e degradação das restaurações. Em razão da presença de fatores diversos agindo no meio oral, todo material restaurador, metálico ou não, sofre uma ação de deterioração em sua superfície ,seja por variação de $\mathrm{pH}$, dieta alimentar, temperatura ou mastigação. Houve evolução de novas ligas metálicas, entre elas o titânio (Ti), que apresenta propriedades físicas e biocompatíveis excelentes, sendo um material muito utilizado em vários setores relacionados àárea odontológica, principalmente na indústria de implantes dentais. Nesse estudo foi avaliada a rugosidade superficial de duas ligas metálicas ( $\mathrm{Ti}$ e $\mathrm{Ni} \mathrm{Cr}$ ) em três fases distintas, através de leituras realizadas pelo rugosímetro de superfície nos corpos de 
prova, submetidos à ciclagem térmica e submersos em saliva artificial à temperatura constante de 37 graus centígrados, por um período de 8 meses. Através dos resultados estatísticos obtidos, conclui-se que não existe diferença entre as ligas, no tocante aos fatores tempo e aspecto visual, havendo somente diferença significante entre as fases I e III do estudo. 


\section{INTRODUÇÃO}

O titânio (Ti) foi isolado na natureza pela primeira vez há cerca de 200 anos, mas a utilização desse material data de apenas quarenta anos. Ele tem sido um dos mais importantes metais utilizados na indústria, devido æ̀ suas atrativas propriedades mecânicas e excelente resistência àcorrosão. $O$ maior ímpeto para o seu desenvolvimento foi dado pelas indústrias aeroespaciais e bélicas, em virtude de ser considerado leve e resistente, oferecendo várias soluções para a engenharia.

A partir do desenvolvimento do processo de fundição das ligas metálicas, iniciou-se o uso de restaurações indiretas como rotina na clínica odontológica. Taggart (1987).

Ao longo dos últimos 40 anos, muitos estudos investigativos sobre corrosão em ligas dentais têm sido publicados, tais como os de Laing (1997); Youssef (1995); Wald (1971). A maioria dos pesquisadores, no entanto, descreve a clássica combinação amálgama / ouro. Em contraponto a tal corrente majoritária, somente alguns estudos relatam a condução de processo corrosivo como resultado do contato entre o implante de titânio intra-ósseo com as ligas utilizadas no sistema de reabilitação protética sobre o implante. A corrosão galvânica entre o implante e a prótese apresenta vital importância, visto que há a possibilidade de ocorrer efeitos biológicos pela 
dissolução de algum componente da liga utilizada. Ligas do tipo Ni Cr são utilizadas na construção de peças protéticas sobre o implante em razão do seu binômio baixo custo / alta resistência. Gerstorfer (1989).

O trabalho em tela apresenta, como uma de suas diretrizes básicas, a contribuição para o estudo das restaurações dentais indiretas (no caso, as ligas metálicas), partindo-se da comparação entre o $\mathrm{Ti}$ e o $\mathrm{Ni} \mathrm{Cr}$, sendo aquele considerado um material moderno, dotado de inúmeras alternativas de uso, da engenharia àárea médica, e possuindo este larga utilização como material restaurador. Steinemann (1989) 


\section{REVISÃO DA LITERATURA}

Taggart, em 1907, desenvolveu o processo de fundição de ligas áuricas e suas substitutas, iniciando o uso de restaurações metálicas como uma prática rotineira na clínica odontológica.

Em 1940, Bothe utilizou o titânio, na forma de implantes, em animais de laboratório, comparando-o com materiais metálicos usados em aplicações cirúrgicas, constatando que o referido metal apresentou boa tolerância e resistência àcorrosão, pelo menos aparentemente.

Beder \& Ploger ,em 1959, sugeriram o uso da centrífuga com indução a calor em câmara a vácuo para a obtenção de copings de titânio; entretanto, tal pesquisa não foi passível de conclusão. Somente na segunda metade da década de 70 , é que passou a haver a obtenção de coroas e próteses parciais conforme sugestão anterior de Beder \& Ploger (1959).

Em 1960, Evans através de estudo sobre corrosão e erosão em ligas metálicas, concluiu que a primeira consiste na destruição de um metal ou liga metálica, por alteração química e eletrolítica acompanhada por perda de corpo superficial. E a erosão foi classificada como sendo uma deformação da superfície metálica em conseqüência de processos estritamente mecânicos, com ausência de alterações químicas. 
Nagai, em 1969, estudando a corrosão de ligas de cobre na cavidade oral, através do processo de perda de peso, verificou que, em meio bucal as mesmas apresentavam perda de peso, sendo que em presença de saliva artificial a perda era significantemente majorada. De conformidade ao referido autor, a saliva humana apresenta a capacidade de inibir a oxidação e a corrosão em superfície de ligas metálicas.

Em 1969, Sedej estudando a corrosão de ligas, concluiu que o processo corrosivo depende da composição e da natureza das ligas, e que a resistência ao referido processo poderia ser aumentada através de técnicas de polimento da superfície.

Wald et al. estudaram, em 1971, quatro tipos de ligas àbase de cobre, manganês e níquel para uso odontológico. Tais ligas foram submetidas a processo de corrosão eletroquímica em solução de saliva artificial a 37 graus centígrados. Os autores verificaram uma presença de corrosão leve e, apesar disso, concluíram que são ligas passíveis de uso na confecção de restaurações metálicas fundidas.

Em 1973, Moffa descreveu que, a partir do avanço das porcelanas dentais na década de 60 e do aumento substancial do custo do ouro nos anos 70 , muitas ligas alternativas, tais como, a prata paládio começaram a ser desenvolvidas.

Fenton, em 1978, estudou as propriedades alergênicas e carcinogênicas provenientes dos metais que compõe as ligas, em especial o níquel e o berílio, gerando muitas controvérsias. A segurança no uso de ligas metálicas e a possibilidade de efeitos adversos àsaúde devido àexposição 
a certos elementos contidos nos materiais têm sido objeto de estudo nos últimos anos inexistindo, todavia, conclusões definitivas a respeito.

Dinelli et al. em 1972, estudando o galvanismo e a corrosão, indicaram o polimento como sendo um método eficaz na diminuição do processo corrosivo na cavidade bucal.

Skinner \& Phillips, em 1973, observaram que, clinicamente, torna-se muito difícil a distinção entre manchamento e corrosão, sendo que tais termos são utilizados indistintamente na literatura odontológica. Segundo os autores, manchas originam-se de pigmentos produzidos por bactérias ou drogas que tenham em sua composição ferro e mercúrio. Manchamentos também ocorrem em razão da deposição de alimentos na superfície da restauração, principalmente em locais de difícil higienização, sendo que o aparecimento de manchas constitui o primeiro passo em direção ao processo corrosivo. Esses autores definem a corrosão como uma deterioração apresentada na superfície do metal.

Oliveira Jr. em 1981, estudou quatro tipos de ligas metálicas ouro, níquel cromo, cobre alumínio e amálgama. O citado autor realizou duas avaliações, uma objetiva, através da espectrofotometria e a outra subjetiva, através da observação visual. Na primeira avaliação, as ligas apresentaram menor alteração de cor, sendo a liga de níquel cromo, a que menor alteração sofreu. Na Segunda avaliação, a liga em ouro apresentou melhores resultados, enquanto que o amálgama e a liga cobre alumínio, os piores.

Phillips, em 1984, afirmou que as ligas metálicas podem reagir com os elementos não metálicos do meio, sofrendo reações químicas, produzindo compostos químicos conhecidos como produtos de corrosão. O autor mostra 
que detritos de alimentos aderem-se firmemente \&̀ restaurações metálicas, proporcionando uma reação acelerada entre os produtos da corrosão e as ligas.

Citou Williams, em1984, a extraordinária evolução do titânio nas áreas médica e odontológica, ressaltando suas principais características, como a excelente biocompatibilidade, a resistência àcorrosão e suas propriedades físicas.

Baran, em 1983, analisando a oxidação entre ligas de níquel - cromo e de níquel de alta pureza, concluiu que o Litecast oxidou mais lentamente do que a liga de níquel pura.

Mjör \& Hensten- Pettersen, em 1983, sugeriram testes e pesquisas sobre os efeitos adversos causados por ligas dentais alternativas, isto é, aquelas compostas com menos de $75 \%$ de metal nobre. Tais trabalhos apresentaram propostas de discussão da evolução de toxidade sistêmica, irritação local, carcinogenicidade e respostas alérgicas. Caracteriza o mais conhecido efeito adverso do uso de ligas alternativas em próteses dentais a reação alérgica, sendo que a freqüência do mencionado efeito não é totalmente conhecida.

Eicher, em 1983, através da revisão de literatura, destacou a dificuldade da obtenção de uma padronização das ligas metálicas usadas em odontologia devido ao alto número de marcas no mercado; só nos Estados Unidos, estão àvenda centenas de ligas dentárias, registradas pela American Dental Association.

Glantz, em 1984, estudando o aumento do custo das ligas em ouro e observando o aparecimento de ligas metálicas de baixo custo, alertou sobre 
o possível risco de reações patológicas associadas ao uso de ligas alternativas contendo principalmente em sua composição níquel, berílio e cádmo, fazendo, também, ressalvas no tocante \$̀ aspectos técnicas.

Jones, em 1986, estudou em Fort Knox U.S.A. a sensibilidade causada pela presença do níquel, concluindo que pacientes com histórico anterior de sensibilidade ao citado metal, necessariamente não apresentariam problemas com o uso de prótese dental que contivesse tal elemento químico.

Greener \& Moser, em 1986, através de pesquisas realizadas na Northwestern University analisaram o uso do titânio como material para restauração sob vários aspectos, comparando as propriedades de resistência, adaptação e eletroquímica.

Vieira em 1987, verificou a existência de modificação nas superfícies de ligas metálicas devido àpresença de agentes externos como o ar, a água, a saliva e soluções ácidas e alcalinas, chamando essas alterações de corrosão. Observou, também, que o nível de corrosão depende da composição das ligas e do tipo de agentes químicos presentes no meio incluindo-se a variação da temperatura.

Baez \& Blackman, em 1989, baseando-se na observação das irregularidades periféricas observou a evolução clínica de copings de titânio em que houve a presença de $90 \%$ de sucesso.

Hildebrand et al., em 1989, estudaram a possível correlação entre reações alérgicas a próteses dentais ou restaurações feitas com um ou mais metais, dentre os quais, o níquel, o cobalto e o crômio. A par da descrição 
de casos clínicos revistos, reações alérgicas como estomatites localizadas e dermatites de contato foram relatadas.

Bergman et al., em 1990, estudaram a evolução in vivo por um período de dois anos de coroas de titânio confeccionadas em 205 pacientes. Através das observações concluíram que, após o referido intervalo, a integridade marginal de todas as coroas foram consideradas excelentes.

Hensten - Pettersen \& Jacobesen, em 1991, através de revisão de literatura, descreveram materiais dentais e acessórios usados na clínica como potenciais causadores de reações adversas nos cirurgiões - dentistas, auxiliares e pacientes. Foi constatado que algumas reações alérgicas ou tóxicas existem, mas não são totalmente explicadas, sendo usualmente dedectadas quando a exposição ao material é intensa.

Lautenschlager \& Monaghan em 1993, estudando as ligas de titânio, discutiram suas principais características, tais como o seu peso leve e sua excelente resistência àcorrosão. Essas vantagens do titânio, associadas à sua excelente biocompatibilidade, abrem caminho para novas pesquisas no desenvolvimento desse metal como material restaurador indireto no uso odontológico.

Youssef, em 1995, estudou a rugosidade superficial de ligas alternativas, submetidas a polimento normal e eletrolítico, através de leitura rugosimétrica, concluindo que, as ligas (Co $\mathrm{Al}$ ) tiveram comportamento semelhante e a rugosidade aumentou na mesma proporção em que se aumentava o tempo de permanência na saliva.

Mulders et al., em 1996, estudaram a influência da composição e do processo de fundição de ligas em paládio e não preciosas quando 
submetidas à corrosão eletrolítica "in vivo“. Mudanças na estrutura cristalográfica entre as ligas foi encontrada, mas o processo de fundição não foi observado efeitos significantes. Contudo ligas de níquel - cromo apresentaram baixa estabilidade àcorrosão.

Laing, em 1997, descreve o titânio como o mais biocompatível e resistente àcorrosão material metálico utilizado para implantes, contudo, a formação protetora de óxido pode ser afetada pelo uso excessivo de agentes preventivos em odontologia, como polimentos profiláticos e aplicação tópica de flúor.

Em 1998, Nelson analisou a implicação clínica de ligas metálicas em próteses dentais através de pesquisa in vitro da citotoxidade em ligas condicionadas.

Geis-Gerstorfer, em 1989, investigou a corrosão galvânica nas próteses confeccionadas em ligas de níquel-cromo em contato com implantes de titânio, medindo através de análises de soluções eletrolíticas e cálculos de curvas de densidade em acordo com a lei de Faraday, chegando-se a conclusão de uma clara diferença na corrosão sofrida entre várias ligas de níquel-cromo em contato com o titânio.

Steinemann, em 1998, descreveu o titânio como sendo um material moderno, apresentando excelentes propriedades físicas, químicas e mecânicas. O autor compara através de uma revisão de vários trabalhos, as vantagens do uso desse material, considerando a escolha do mesmo como sendo a melhor opção.

Wataha \& Lockwood, em 1998, estudaram o efeito do $\mathrm{pH}$ sobre a superfície das ligas, expondo ligas nobres e não nobres em soluções ácidas, 
variando de $\mathrm{pH}$ de 1 à7. Através desse estudo, os autores concluíram que ligas nobres apresentam boa resistência àacidez, permanecendo intactas; contudo, ligas com base de níquel liberaram alta quantidade desse referido metal durante sua exposição ao pH ácido, com variação de 1 à4.

Wataha et al. em 2000, estudaram as propriedades da biocompatibilidade em ligas dentais, concluindo que para a minimização dos riscos biológicos, o cirurgião-dentista deveria selecionar as ligas dentais com baixa corrosão. Isto pode ser conseguido através do uso de ligas nobres ou semi nobres com fase simples na microestrutura. Contudo, há exceções, e a escolha da liga deve ser feita caso a caso, usando como base as informações sobre sua corrosão e biocompatibilidade fornecida pelo fabricante. 


\section{PROPOSIÇÃO}

Em decorrência do constante processo de evolução de novos materiais restauradores indiretos na odontologia, entre eles as ligas metálicas, e o aprimoramento das técnicas de sua confecção, associados à busca sempre incessante de um material ideal, principalmente quanto à longevidade e durabilidade no meio bucal, esse trabalho tem como objetivo estudar duas ligas de titânio (Ti) e níquel-cromo (Ni $\mathrm{Cr}$ ) acondicionadas em saliva artificial, submetidas àciclagem térmica e período de tempo sob os seguintes aspectos da superfície das ligas:

1. Análise do efeito tempo (fase) sobre a superfície das ligas.

2. A existência ou não de diferença entre as ligas.

3. A existência ou não de diferença entre as fases I (início), II (4 meses) e III (8 meses).

4. A verificação de possíveis alterações no aspecto visual dos corpos de prova. 


\section{MATERIAL E MÉTODOS}

\subsection{Material}

Para a realização desse trabalho, utilizou-se principalmente da infraestrutura de um laboratório de prótese dental. Foram realizadas inclusões com revestimentos e fundições próprias para cada liga utilizada ( $\mathrm{Ti}$ e $\mathrm{Ni} \mathrm{Cr}$ ).

\subsubsection{Ligas}

Foram utilizadas para esse trabalho dois tipos de ligas, uma em titânio (Ti) e a outra em níquel-cromo ( $\mathrm{Ni} \mathrm{Cr}$ ), para uso na odontologia. A tabela 4.1 mostra as ligas, o fabricante de cada uma delas e sua denominação utilizada no estudo. Figura 1. 
Figura 1 - Aspectos das ligas Ti e Ni Cr em seu estado inicial (comercial).

TABELA 4.1 - Descrição das ligas

\begin{tabular}{c|c|c}
\hline Liga & Denominação & Fabricante \\
\hline Níquel Cromo & LITECAST B & Ivoclar North America Inc. \\
\hline Titânio & REMATITAN Ti 1 & Dentaurum - Pforzheim- \\
& & R.F.A \\
\hline
\end{tabular}


A Tabela 4.2 indica a composição dos metais que compõe as ligas.

TABELA 4.2 - Composição

\begin{tabular}{|c|c|c|c|}
\hline \multicolumn{2}{|c|}{ Níquel Cromo } & \multicolumn{2}{|c|}{ Titânio } \\
\hline $\mathrm{Ni}$ & $77,4 \%$ & $\mathrm{Ti}$ & $99,5 \%$ \\
\hline Co & - & & \\
\hline $\mathrm{Cr}$ & $12,8 \%$ & & \\
\hline Mo & $4,0 \%$ & & \\
\hline $\mathrm{Al}$ & $3,3 \%$ & & \\
\hline Si & $<1,0 \%$ & & \\
\hline $\mathrm{Mn}$ & - & & \\
\hline $\mathrm{Fe}$ & $<1,0 \%$ & & \\
\hline $\mathrm{Be}$ & $1,8 \%$ & & \\
\hline $\mathrm{Ga}$ & - & & \\
\hline $\mathrm{Nb}$ & - & & \\
\hline W & - & & \\
\hline Outr & & & \\
\hline
\end{tabular}




\subsubsection{Padrão de cera}

Retângulos de cera foram recortados em comprimentos iguais de 5,0 $\mathrm{mm}$ e largura de 2,5 mm. Cada retângulo foi incluído e fundido de acordo com as técnicas laboratoriais, originando assim os corpos de prova.

\subsubsection{Revestimentos}

\begin{tabular}{|c|c|c|}
\hline & Fabricante & Marca Comercial \\
\hline Ni Cr & Termocast & Polidental Ind. E Com. \\
& & Ltda. \\
\hline Titânio & Rematitan Plus & $\begin{array}{c}\text { Dentaurum- Pforzheim- } \\
\end{array}$ \\
& & R.F.A \\
\hline
\end{tabular}


Figuras 2a e 2b - Revestimentos para inclusão de $\mathrm{Ti}$ e $\mathrm{Ni} \mathrm{Cr}$

4.1.4 Acabamento e polimento

Foram realizados o acabamento e polimento como mostram as figuras 3 e 4, tomando-se sempre o cuidado de utilizar instrumentos rotatórios exclusivamente para cada tipo de liga e nunca o mesmo instrumento para as duas ligas.

Figura 3 - Instrumentos rotatórios para acabamento e polimento de Ti 
Figura 4 - Instrumentos rotatórios para acabamento e polimento de $\mathrm{Ni} \mathrm{Cr}$

\subsubsection{Saliva artificial}

A saliva artificial foi confeccionada seguindo a composição proposta no trabalho realizado por Youssef (1995), em que os corpos de prova foram mantidos submersos por um período de 08 meses, à uma temperatura constante de $37^{\circ} \mathrm{C}$. A tabela 4.3 mostra a composição da saliva artificial. 
TABELA 4.3 - Composição da saliva artificial

\begin{tabular}{c|c}
\hline Constituintes & Quantidade \\
\hline Pectina & $1,0 \mathrm{~g}$ \\
\hline Colesterol & $0,1 \mathrm{~g}$ \\
\hline Uréia & $0,5 \mathrm{~g}$ \\
\hline Glicose & $0,2 \mathrm{~g}$ \\
\hline Bicarbonato de Sódio & $0,1 \mathrm{~g}$ \\
\hline Cloreto de Sódio & $0,8 \mathrm{~g}$ \\
\hline Fosfato Monossódico $\left(\mathrm{H}_{2} \mathrm{O}\right)$ & $0,5 \mathrm{~g}$ \\
\hline Sulfato de Amônia & $0,3 \mathrm{~g}$ \\
\hline Soro sangüíneo & $10,0 \mathrm{ml}$ \\
\hline Água q.s.p. & 1 litro \\
\hline
\end{tabular}




\section{Aparelhos}

4.1.6a Material plástico para acondicionar os corpos de prova

A figura 5 mostra os nichos separados entre si e totalmente confeccionados em plástico, nas quais foram acondicionados os corpos de prova.

Figura 5 - Material plástico acondicionador dos corpos de prova 
4.1.6b Ciclagem térmica

A figura 6 mostra o aparelho de ciclagem térmica utilizado. Cada ciclo corresponde a 1 minuto em 5 graus centígrados e a 1 minuto em 55 graus centígrados.

Figura 6 - Aparelho de ciclagem térmica marca MCT 2 - AMM Instrumental $\left(5^{\circ} \mathrm{C}\right.$ e $\left.55^{\circ} \mathrm{C}\right)$ 


\subsection{6c Estufa}

Os recipientes plásticos com as divisórias em que os corpos de prova ficaram submersos em saliva artificial foram armazenados no interior de uma estufa, àtemperatura constante de $37^{\circ} \mathrm{C}$, averiguada rotineiramente como mostra a figura 7.

Figura 7 - Estufa utilizada da marca Hereus * modelo RT 360 
4.1.6d Aparelho de leitura rugosimétrica

As leituras das superfícies metálicas dos corpos de prova foram feitas através de um aparelho denominado rugosímetro, da marca Surftest 211, série 178, fabricado pela Mitutoyo do Brasil. Esse aparelho consiste em uma ponta palpadora, que se ajusta perfeitamente ̀̀ superfícies planas, com movimento de leitura automático, apresentando um leitor digital. Suas medições podem variar de acordo com a distância a ser verificada, atentando-se para a necessidade de se calibrar o aparelho. Devido àsua leitura imediata, feita pela ponta palpadora, os resultados já aparecem instantaneamente no visor digital, facilitando sobremaneira a interpretação dos resultados. O aparelho mais detalhado está na figura 8.

Figura 8 - Detalhes do aparelho de leitura Surftest 211, série 178 (Mitutoyo do Brasil) 


\subsection{Método}

Foram confeccionados 36 retângulos em cera com as seguintes dimensões: 5,0 mm de comprimento, 2,5 $\mathrm{mm}$ de largura e a espessura igual àda placa de cera número 7 utilizada. Esses retângulos foram enviados ao laboratório de prótese dental, devidamente acondicionados, evitando-se maiores alterações, sendo em seguida incluídos em revestimento e submetidos ao processo de fundição, sendo utilizados dois tipos de ligas metálicas, o titânio ( $\mathrm{Ti}$ ) e o níquel-cromo (Ni $\mathrm{Cr}$ ). O processo de fundição para obtenção dos corpos de provas (centrífuga Easyti - FLLI MANFREDI Italy) e o acabamento e polimento foram realizados de acordo com o processo laboratorial seguindo-se padrões pré-determinados. Realizou-se uma única fundição em titânio e outra em níquel-cromo, ou seja, os dezoito corpos de prova de cada liga foram obtidos em um só processo de fundição. Quando finalizados, os corpos de prova foram numerados, através de um instrumento cortante rotatório em carbide em baixa rotação, de 1 à36 na superfície não polida e identificados da seguinte forma: de 1 à18 (ligas de Ti) e de 19 à36 (ligas em Ni Cr). Foi realizada a primeira leitura (fase I) das superfícies e adotando-se o mesmo procedimento nas fases subsequentes. Ao todo, foram realizadas cinco leituras em lugares diferentes de $0.25 \mathrm{~mm}$ em cada corpo, sempre no mesmo sentido (figura 9), obtendo-se, assim, uma média. Em seguida os corpos foram submetidos àciclagem térmica de 400 ciclos (quente e frio), de 1 minuto à ${ }^{\circ} \mathrm{C}$ e de 1 minuto $255^{\circ} \mathrm{C}$. Utilizando o dispositivo de armazenamento de plástico, os corpos de prova ficaram 
submersos individualmente em saliva artificial, no interior da estufa, a uma temperatura constante de 37 graus centígrados.

Os corpos ficaram assim submersos e armazenados durante um período de 4 meses, na qual foram secados e submetidos ànova leitura (fase II) conforme anteriormente descrito. Nova ciclagem térmica foi realizada com mais 400 ciclos (de 1 minuto à ${ }^{\circ} \mathrm{C}$ e de 1 minuto à $55^{\circ} \mathrm{C}$ ), voltando os corpos a serem armazenados da mesma forma por mais 4 meses. Ao término desse último período nova leitura (fase III) foi feita, à semelhança das anteriores.

- Fase I (início) em que os corpos de prova estavam com acabamento e polimento realizados pelo laboratório

- Fase II (após 400 ciclos de 1 minuto à5 ${ }^{\circ} \mathrm{C}$ de temperatura e 1 minuto à $5^{\circ} \mathrm{C}$ e armazenados por mais 4 meses)

- Fase III (após 400 ciclos de 1 minuto à5 ${ }^{\circ} \mathrm{C}$ de temperatura e 1 minuto à $5^{\circ} \mathrm{C}$ e armazenados por mais 4 meses) 
Figura 9 - Dispositivo confeccionado para padronização das leituras no corpo de prova. 


\section{RESULTADOS E DISCUSSÃO}

Para esse estudo foi realizada a média das cinco leituras da rugosidade obtida em $\mu \mathrm{m}$ (micrômeros) nos corpos de prova de liga de titânio (Ti) e de níquel - cromo ( $\mathrm{Ni} \mathrm{Cr}$ ), através das fases I, II e III.

Trabalhou-se com a média da rugosidade das cinco leituras realizadas em cada corpo de prova. As médias por corpo de prova e por tipo de liga encontram-se no Apêndice.

As médias e desvios- padrão da rugosidade para cada fase e material da liga encontram-se na Tabela 5.1. Tais médias foram representadas através do gráfico de perfis da figura 10.

TABELA 5.1 - Médias e desvios- padrão da rugosidade para cada fase e material da liga

\begin{tabular}{c|l|c|c|c}
\hline Material da liga & Medidas resumo & Fase I & Fase II & Fase III \\
\hline Titânio & Média & 0.339 & 0.371 & 0.389 \\
\hline & Desvio padrão & 0.031 & 0.066 & 0.081 \\
\hline & & & & \\
\hline $\mathrm{Ni} \mathrm{Cr}$ & Média & 0.322 & 0.332 & 0.391 \\
\hline & Desvio padrão & 0.050 & 0.061 & 0.121 \\
\hline
\end{tabular}




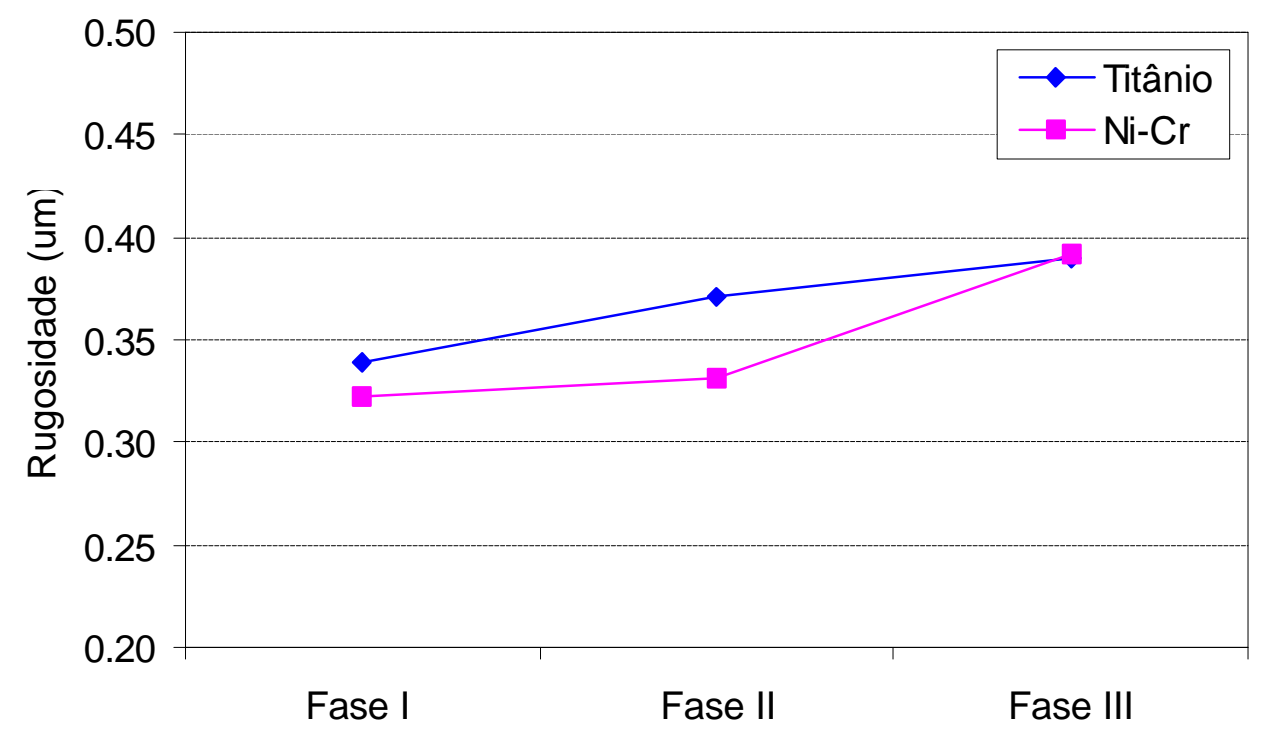

Figura 10 - Médias em função de Fase e Tipo de Liga

Em relação àfigura 1, ocorreram comportamentos semelhantes entre as ligas de titânio e níquel- cromo, comprovando que, ambas possuem boa aceitação em meio àsaliva artificial.

Como neste caso os mesmos corpos de prova foram medidos em três diferentes momentos (início, fase II e III) trata-se de um estudo longitudinal. Esta análise estatística considera a dependência entre as observações.

A análise foi realizada através do procedimento GLM do software SAS (análise multivariada de perfis). Os resultados observados estão na Tabela 5.2. 
TABELA 5.2 - Resultados da análise de medidas repetidas

\begin{tabular}{l|c|c}
\hline Fonte de variação & $\mathbf{p}$ & Conclusão \\
\hline Liga & 0.2388 & $\mathrm{NS}$ \\
\hline Fase & 0.0019 & ${ }^{\star *}$ \\
\hline Liga x Fase & 0.5739 & $\mathrm{NS}$ \\
\hline & & \\
\hline Contrastes (Fase) & $\mathbf{p}$ & Conclusão \\
\hline I x II & 0.0894 & $\mathrm{NS}$ \\
\hline I X III & 0.0012 & ${ }^{\star *}$ \\
\hline II x III & 0.0692 & $\mathrm{NS}$ \\
\hline
\end{tabular}

** Hipótese significante ao $1 \%$

NS Hipótese não significante

Na figura 11 ilustrou-se a média das duas ligas (já que não foram observadas diferenças significativas entre ligas). Em torno da média foram construídos intervalos de confiança da média (95\%).

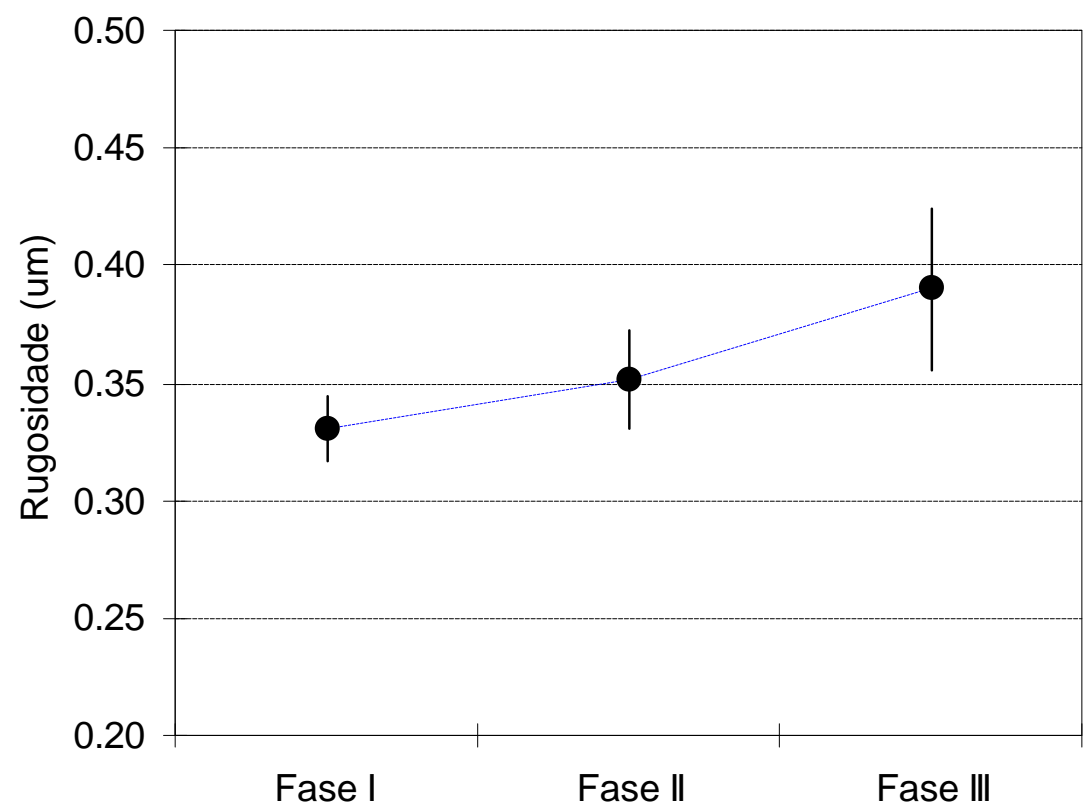

Figura 11 - Intervalos de confiança (95\%) para a média das duas ligas nas três fases 
Atualmente a diversificação e a complexidade nos tratamentos reabilitadores indiretos do elemento dental oferecem uma variedade muito grande de alternativas. O mais importante e principal objetivo em uma restauração consiste na sua longevidade, muitas vezes colocada em segundo plano, em razão da estética, como se esse fosse um fator determinante. A estética deve ser nos dias atuais uma aliada importante, mas não o objetivo principal.

O cirurgião dentista utiliza rotineiramente os metais na realização de restaurações exigindo-se assim, um conhecimento geral sobre as características químicas, físicas, mecânicas e estruturais. (Vieira, 1967, p.13).

Podemos definir a liga, para uso odontológico, como sendo uma substância metálica que contém em sua composição dois ou mais elementos, na qual pelo menos um desses consiste em um metal mutuamente solúvel na condição de fundido.

Com isso, podemos afirmar que as ligas metálicas, sejam elas denominadas nobres, semi-nobres ou alternativas, são utilizadas há muito tempo em trabalhos reabilitadores dentais, tendo sua eficácia em relação ao quesito longevidade comprovada, tanto clínica como laboratorialmente.

Ligas em ouro e suas derivações foram desenvolvidas no início do século XX através de processo de fundição. Desde então, restaurações metálicas têm sido utilizadas nos consultórios dentários como reabilitador dental.

Com o avanço das porcelanas dentais na década de 60 e o aumento do preço do ouro na década de 70 , ligas alternativas, como as de paládio e 
as de metais com base em níquel-cromo ( $\mathrm{Ni} \mathrm{Cr}$ ) e cromo-cobalto ( $\mathrm{Cr} \mathrm{Co}$ ) desenvolveram - se rapidamente. Moffa ( 1973)

Devemos sempre observar que os tipos de restaurações dentais, sejam eles quais forem, estarão sempre sujeitos a uma série de fatores externos, com influência direta sobre os materiais, isso tudo em virtude de a restauração encontrar-se na cavidade oral. Assim sendo, pelas características encontradas na cavidade bucal, tais como, o teor de $\mathrm{pH}$, acidez, temperatura, mastigação, todos os materiais que nela se encontram sofrem diversos tipos de alterações, dentre os quais manchamento e corrosão . Skinner \& Phillips (1973)

Outro ponto de grande discussão atualmente reside nas vantagens e desvantagens dos materiais, ou seja, dos tipos de metais que compõem as ligas. As principais considerações giram em torno do grau de corrosão e da potencialidade carcinogênica e alérgica das ligas utilizadas em odontologia, especialmente as que têm como base o níquel e berílio. Alguns autores não descrevem reações alérgicas em resposta ao níquel, contudo, outros autores reportam uma alta freqüência de reações alérgicas em pacientes com o mesmo perfil de estudo. As ligas em níquel-cromo contêm aproximadamente 60 a 80 \% de níquel em sua composição, e se essa base não apresentar resistência suficiente à corrosão, produtos resultantes desse processo podem iniciar sensibilidade alérgica. Blanco (1982) ; Fenton (1978)

A segurança e a possibilidade de ocorrerem efeitos nocivos, em conseqüência da exposição de certos elementos contidos nos materiais usados em odontologia, têm sido motivo de preocupação nos últimos anos, não somente dos pesquisadores, mas da opinião pública também, citando- 
se como exemplo dessa polêmica, a utilização do mercúrio no amálgama dental.

Quando selecionamos as ligas dentais para cada situação clínica, três fatores principais levam a uma decisão : o custo, as propriedades físicas das ligas, e a biocompatibilidade. Infelizmente, o fator custo tende freqüentemente a ser o fator prepoderante nos últimos tempos, portanto, a escolha da liga não pode ser determinada exclusivamente pelo seu custo, em detrimento dos outros dois fatores. Glantz (1984)

Nos anos 60 o termo biocompatibilidade não era utilizado com freqüência, utilizando-se somente o termo toxidade. Geralmente a biocompatibilidade de um material usado na clínica dentária é medida com base na citotoxidade localizada, ou seja, de acordo com as reações sistêmicas e com o potencial alergênico e carcinogênico. Portanto, um material restaurador deve possuir características não prejudiciais àpolpa e tecidos moles, não devendo conter substâncias tóxicas dispersíveis que possam ser liberadas e absorvidas pelo sistema circulatório, sendo isentos de agentes potencialmente causadores de reações alérgicas e carcinogênicas. Phillips (1984). Reações alérgicas como estomatites localizadas e dermatites de contato, causadas pelo uso de próteses ou restaurações confeccionadas com níquel, cobalto e crômio, foram descritas por Hildebrand em 1989

A biocompatibilidade dos metais não costumava ser alvo de muitos questionamentos, porém, hoje em dia, a citotoxicologia das ligas dentais caracteriza fator de discussão. Nelson (1998). Eicher em 1983 destacou a dificuldade na padronização das ligas metálicas utilizadas em odontologia, 
em razão da variedade de marcas existentes. Há, entretanto, a necessidade da realização de mais testes, tanto clínica como laboratorialmente para comprovar a biocompatibilidade e a toxidade da liga em meio bucal. Nota-se ainda que Mjör et al em 1983 sugeriram testes em ligas metálicas compostas por menos de $75 \%$ em metal nobre.

Hensten \& Jacobesen em 1991 afirmaram que diversos materiais utilizados rotineiramente pelo cirurgião - dentista, auxiliares e inclusive pacientes, são possíveis causadores de reações adversas, sendo que algumas não são totalmente explicadas, mas sim detectadas quando da exposição ao material .

As propriedades físicas das ligas dentais são características decisivas no critério de seleção pelo cirurgião dentista. Fatores como a dureza, rigidez, resiliência e coeficiente de expansão térmica influem na decisão em virtude da situação clínica, como por exemplo, no caso da seleção de uma liga para a confecção de estrutura em uma prótese fixa a ser cimentada pela técnica adesiva, em razão do alto módulo de elasticidade dos cimentos resinosos.

Um dos objetivos desse trabalho consiste na contribuição para o estudo de novas alternativas nas restaurações dentais, no caso, as ligas metálicas, através da aplicação do titânio (Ti) em relação ao níquel-cromo (Ni Cr), largamente utilizado e reconhecido como material restaurador.

A utilização das aplicações do titânio na área médica e odontológica foi extremamente aumentada nos últimos anos, em função de sua excelente biocompatibilidade, resistência àcorrosão e ótimas propriedades físicas e mecânicas. 
Com os resultados obtidos, primeiramente podemos verificar que entre as ligas utilizadas nesse trabalho ( $\mathrm{Ni} \mathrm{Cr}$ e $\mathrm{Ti}$ ), a primeira é largamente mais difundida e usada pelo cirurgião-dentista em sua clínica diária, por apresentar características bem conhecidas, facilitando o seu manuseio pelo profissional. Vieira (1987). Quanto ao uso da liga de titânio ,esta começa a ser descoberta pela odontologia para servir como material restaurador indireto, sendo que em outras áreas sua utilização já possui relevo.

Dentre suas principais características ,as ligas em estudo não apresentaram alto grau de rugosidade e corrosão. Em 1960, Evans descreveu a corrosão sendo uma destruição do metal ou liga metálica acompanhada por perda de corpo superficial, e a erosão uma deformação da superfície metálica em conseqüência de processos estritamente mecânicos, com ausência de alterações químicas.

Como nesse trabalho estudamos somente as ligas submersas em saliva, sem a utilização, por exemplo, da ciclagem mecânica ou qualquer dispositivo que acarretasse desgaste na superfície do metal, podemos concluir que as mesmas sofreram processo químico, ocorrendo possivelmente corrosão em sua superfície. Nagai em 1969, através de seu estudo da corrosão em ligas de cobre em meio bucal, verificou que as mesmas apresentavam perda de peso em tal meio, e na presença da saliva artificial, essa perda era bem maior, concluindo, assim, que a saliva bucal possui a capacidade de inibir uma maior oxidação e corrosão nas superfícies de ligas metálicas.

Da observação da superfície das ligas, tanto de titânio como de níquel-cromo, não se notou oxidação, e Baran em 1983, detectou uma maior 
oxidação em liga de níquel pura em relação \$̀ de níquel-cromo, entre elas o Litecast, utilizada neste trabalho. Oliveira, Jr em 1984 através de seu estudo sobre quatro tipos de ligas metálicas, verificou algum tipo de variação, sendo que na avaliação estritamente visual, observou melhores resultados em ligas do tipo nobre. Sedej em 1969 e também Dinelli em 1972 descreveram que o processo de corrosão depende da composição e da natureza da liga, e que a técnica de acabamento e polimento é uma maneira de se diminuir esse processo. Lucas et al., em 1985 também citam em seu estudo a forte tendência àcorrosão em ligas compos tas por níquel.

Houve provavelmente a liberação de níquel durante a realização do trabalho, por estar a liga de níquel-cromo submersa durante 8 meses em solução, utilizando-se como parâmetro o trabalho de Wataha em 1998, em que o autor constatou a liberação do níquel da liga composta de níquelcromo exposta àsolução de $\mathrm{pH}$ de 1 à7 por apenas trinta minutos. Wald em 1971 também descreveu que ligas àbase de cobre, manganês e níquel, submetidas a processo de corrosão eletrolítica em saliva artificial, apresentaram presença de corrosão leve, podendo ser estas ligas utilizadas na confecção de restaurações dentais indiretas.

Mulders et al. em 1996 compararam ligas em paládio e com metais não preciosos, como o níquel-cromo, afirmando que o níquel-cromo, comparado com uma liga nobre ou semi- nobre, possui mais vulnerabilidade ao processo de corrosão.

O titânio comportou-se de maneira quase idêntica ao níquel-cromo, levando-se a presunção de que sua utilização como agente restaurador indireto, seja para incrustações, corpo de próteses, "copings" e outros, 
possui boa aceitação de conformidade com Greener que, em 1986, estudando o Ti como material restaurador indireto, afirmou possuir o mesmo boas propriedades de resistência e de adaptação. Também Baez, em 1989, através de observações da evolução clínica de coroas de titânio, constatou a presença de $90 \%$ de sucesso, baseando-se nas irregularidades periféricas.

Lautenschlager \& Monaghan em 1993 estudando o titânio, enfatizaram as vantagens do seu uso como material restaurador dental indireto, baseando-se em suas propriedades conhecidas.

Estudando durante um período de 2 anos, coroas confeccionadas em titânio em 250 pacientes, Bergman em 1990 através do método de observação, concluiu que a integridade marginal, isto é, a não ocorrência de processo de degradação dessas coroas ,foi considerada excelente.

As observações e conclusões desses autores associados aos resultados obtidos nesse estudo, indicam que o titânio, cujo desenvolvimento e aprimoramento de sua técnica de trabalho desde muito é estudada, como material restaurador mais recente em relação ao níquel-cromo, possui características e indicações para que seu uso seja mais freqüente na clínica Bothe (1940); Beder \& Ploger (1959).

Geis - Gestorfer, em 1989, investigou a corrosão galvânica nas próteses confeccionadas em níquel-cromo em contato com implantes de titânio, concluindo haver uma clara diferença na corrosão das ligas de níquel-cromo quando em contato com o titânio, levando a crer ser de vital importância a escolha do metal que servirá como base da prótese, sobre um implante ósseo-integrado, sendo ela qual for. 
Analisando-se ainda a tabela 5.2, pode-se afirmar que ambas as ligas, em relação \&̀ fases início, 4 meses e 8 meses, apresentam-se de forma semelhante. Youssef em 1995 observou em seu trabalho, através de leitura rugosimétrica em ligas de cobre-alumínio, que a rugosidade aumentou na mesma proporção do tempo de permanência na saliva. Essa curva também foi observada nesse trabalho entre o titânio e níquel-cromo, que embora sendo materiais de composição distintas, apresentaram semelhança na relação rugosidade $\mathrm{x}$ fase.

Podemos ressaltar que, as médias obtidas ( Apêndice ), em algumas leituras apresentaram certa discrepância, ou seja, resultados não totalmente lineares. Esses resultados são explicados em parte, pelo aspecto da superfície das ligas vistas em Microscopia Eletrônica de Varredura ( Anexo ).

Um aspecto a ser ressaltado é o da biocompatibilidade das ligas estudadas. Sem nenhuma dúvida, podemos afirmar que o titânio é um material muito superior em se tratando de biocompatibilidade. Williams em 1984 citou a extraordinária evolução do titânio nas áreas médica e odontológica, ressaltando características como a excelente biocompatibilidade. Em relação ao níquel-cromo, Jones em 1986 estudou a sensibilidade de pacientes frente àpresença do $\mathrm{Ni}$, concluindo que muitos apresentaram suscetibilidade, contudo, isso não impedia o uso com sucesso de uma prótese dental contendo níquel.

Wataha em 2000 sugeriram que o cirurgião - dentista, para minimizar riscos biológicos, deveria selecionar ligas metálicas com baixa corrosão, utilizando para isso, ligas nobres ou semi-nobres, ou então ligas com comprovada biocompatibilidade, como os de titânio. 
Novos estudos deverão ser realizados, mas através da presente discussão em que pudemos verificar a quase unanimidade dos autores em relação æ̀ principais características dos metais utilizados ( Ti e Ni Cr ), pode se desde já afirmar com segurança que as ligas, respeitando suas indicações e uso, são materiais de escolha na clínica diária do cirurgiãodentista. 


\section{CONCLUSÕES}

De acordo com os resultados obtidos nesta pesquisa (Tabela 5.2 pág. 29) e através da análise estatística realizada, podemos concluir que:

1. As duas ligas utilizadas, $\mathrm{Ni} \mathrm{Cr}$ e Ti, com composição diferente entre si, comportaram-se de forma semelhante em relação ao fator tempo (Liga $\mathrm{x}$ Fase) $(p=0.5739)$

2. Não foram observadas entre as ligas diferenças significativas ao longo do trabalho, comportando-se as mesmas de forma semelhante ( $p=$ $0.2388)$.

3. Ocorreu variação significante $(p<0,01)$ nas ligas somente quando comparadas as fases I (início) e III (8 meses).

4. Quanto ao aspecto meramente visual da superfície, o níquel-cromo apresentou melhor brilho que o titânio, mas não foram observadas alterações de ambas as ligas nos corpos de prova em relação ao início e final do estudo. 


\section{ANEXOS}


I - M.E.V. da superfície do Ti ( x 1.50020 KV)

II - M.E.V. da superfície do Ti (x 3.00019 KV) 
III - M.E.V. da superfície do Ni $\operatorname{Cr}(x 1.50019$ KV)

IV - M.E.V. da superfície do $\mathrm{Ni} \mathrm{Cr}$ (x $3.00015 \mathrm{KV}$ ) 
V - A e B - Aspectos visuais da superfície dos corpos de prova $\mathrm{Ti}$ e $\mathrm{Ni} \mathrm{Cr}$ início (Fase I) 
VI - A e B - Aspectos visuais da superfície dos corpos de prova $\mathrm{Ti}$ e $\mathrm{Ni} \mathrm{Cr}$ após 8 meses ( Fase III ) 


\section{REFERÊNCIAS BIBLIOGRÁFICAS *1}

1. ANUSAVICE, K.J. (Ed.) Phillips materiais dentários. 10.ed. Rio de Janeiro: Guanabara Koogan, 1998. 412p.

2. ASSOCIAÇÃO BRASILEIRA DE NORMAS TÉCNICAS. Normas abnt sobre documentação. São Paulo: ABNT, 1988.

3. BARAN, G. Oxidation kinetics of some Ni-Cr alloys. J Dent Res, v.62, n.1, p.51-55, Jan. 1983.

4. BEDER, O.E.; PLOYER, W.J. Intraoral titanium implants. Oral Surg Oral Med Oral Pathol, v.12, n.7, p.787-799, 1959.

5. BERGMAN, B.; NILSON, H.; BESSING, C.; LUNDQUIST, P.; ANDERSON, M. Titanium copings veneered with procera ceramics: a longitudinal clinical study. Int J Prosth odont, v.7, n.2, p.115-119, Mar./Apr. 1994.

* De acordo com NBR-6023 da Associação Brasileira de Normas Técnicas, 1989. Abreviatura de periódicos segundo "Index to Dental Literature". 
6. BLACKMAN, R.; BAEZ, R.; BARGHI, N. Marginal accuracy and geometry of cast titanium copings. J Prosthet Dent, v.67, n.4, p.435-440, Apr. 1992.

7. BLANCO-DALMAU, L. The nickel problem. J Prosthet Dent, v.48, n.1, p.99-101, July 1982.

8. BOTHE, T.R.; BEATON, L.E.; DAVENPORT, H.A. Reaction of bone to multiple metallic implants. Surg Gynecol Obstet, v.71, n.6, p.598-602, 1940.

9. DINELLI, W.; GABRIELLI, F.; FONTANA, U.F.; ROLFSEN, R.C. Galvanismo e corrosão na cavidade oral (Aspectos gerais). Rev Fac Farm Odontol Araraquara, v.6, n.2, p.195-201, Jul./Dez. 1972.

10. EICHNER, K. Applications of metal alloys in dentistry - a review. Int Dent J, v.33, n.1, p.1-10, Mar. 1983.

11. EVANS, U.R. The corrosion and oxidation of metals: scientific principles and practical applications. London: Edward Arnold, 1960. p.1-58.

12. FENTON, A.H.; JEFFREY, J. Allergy to a partial denture casting: case report. Dent J, v.44, n.10, p.466-468, Nov. 1978.

13 - GEIS-GERSTORFER, J.; WEBER, H. In vitro corrosion behavior of four $\mathrm{Ni}$-Cr dental alloys in lacticacid and sodium chloride solutions. Dent Mater, v.3, n.6, p.289-295, Dec. 1987. 
14. GEIS-GERSTORFER, J.; WEBER, H.; SAUER, K. In vitro substance loss due to galvanic corrosion in $\mathrm{Ti}$ Implant / $\mathrm{Ni}-\mathrm{Cr}$ supra construction systems. Int J Oral Maxillofac Implants, v.4, n.2, p.119-123, Summer 1989.

15. GLANTZ, P.O. Intraoral behaviour and biocompatibility of gold versus non precious alloys. J Biol Buccale, v.12, n.1, p.3-16, Mar. 1984.

16. HENSTEN-PETTERSEN, A.; JACOBSEN, N. Toxic effects of dental materials. Int Dent J, v.41, n.5, p.265-273, Oct. 1991.

17. HILDEBRAND, H.F.; VERON. C.; MARTINS, P. Nickel, chromium, cobalt dental alloys and allergic reactions: an overview. Biomaterials, v.10, n.8, p.545-548, Oct. 1989.

18. JOHANSSON, B.I.; LUCAS, L.C.; LEMONS, J.E. Corrosion of copper, nickel and gold dental casting alloys: an in vitro and in vivo study. $\mathbf{J}$ Biomed Mater Res, v.23, p.349-361, Dec. 1989. Suplemento A3.

19. JONES, T.K.; HANSEN, C.; SINGER, M.; KESSLER, H. Dental implications of nickel hypersensitivity. J Prosthet Dent, v.56, n.4, p.507-509, Oct. 1986. 
20. LAING, P.G. Tissue reaction to biomaterials. In: Symposium on Retrieval and Analysis of Orthopedic Implants, 1997, Gaithersburg. Procedings... Gaithersburg: National Bureau of Standards, 1997. p.31-39.

21. LAUTENSCHLAGER, E.P.; MONAGHAN, P. Titanium and titanium alloys as dental materials. Int Dent J, v.43, n.3, p.245-253, June 1993.

22. MJOR, I.A.; HENSTEN-PETTERSEN, A. The biological compatibility of alternative alloys. Int Dent J, v.33, n.1, p.35-40, Mar. 1983.

23. MOFFA, J.P.; LUGASSY, A.A.; GUCKES, A.D. An evaluation of non precious alloys for use with porcelain venners. Part I. Physical properties. J Prosthet Dent, v.30, n.4, p.424-431, Oct. 1973.

24. MULDERS, C.; DARWISH, M.; HOLZE, R. The influence of alloy composition and casting procedure upon the corrosion behaviour of dental alloys: an in vitro study. J Oral Rehabil, v.23, n.12, p.825-831, Dec. 1996.

25. NAGAI, K. Corrosion testing in the mouth. J Nihon Univ Sch Dent. v.11, n.4, p.129-139. Dec. 1969.

26. NAKAJIMA, H.; OKABE, T. Titanium in dentistry: development and research in the U.S.A. Dent Mater J, v.15, n.2, p.77-90, Dec. 1996. 
27. NELSON, S. WATAHA, J.; LOCKWOOD, P. Accelerated toxicity testing of casting alloys and reduction of intraoral release of elements. $\mathbf{J}$ Prosthet Dent, v.81, p.715-20, June 1999.

28. OLIVEIRA Jr., C.S. Avaliação objetiva (espectrofotométrica) e subjetiva (visual) das alterações no brilho de quatro ligas metálicas odontológicas (ouro, níquel-cromo, cobre-alumínio e amálgama) mantidas no meio bucal por 6 meses. Bauru, 1981. 87p. Tese (Doutorado) - Faculdade de Odontologia de Bauru da Universidade de São Paulo.

29. PHILLIPS, R.W. Materiais dentários de Skinner. Trad. De Dioracy Fonterrada Vieira. Rio de Janeiro: Interamericana, 1984. 467p.

30. RECLARU, L.; MEYER, J.M. Study of corrosion between a titanium implant and dental alloys. J Dent, v.22, n.3, p.159-168, June 1994.

31. SKINNER, E.W.; PHILLIPS, R.W. The science of dental materials. Philadelphia: Saunders, 1973. p.289-300.

32. STEINEMANN, S.G. Titanium - the material of choice? Periodontol 2000, v.17, p.7-21, June 1998.

33. TAGGART, W.H. A new and accurate method of making gold inlays. Dent Cosmos, v.49, n.11, p.1117-1121, Nov. 1907. 
34. TAIRA, M.; MOSER, J.B.; GREENER, E.H. Studies of Ti alloys for dental castings. Dent Mater, v.5, n.1, p.45-50, Jan. 1989.

35. VIEIRA, D.F. Metais e ligas metálicas: noções básicas para dentistas. 12.ed. ver. Atual. São Paulo : Edgar Blucher, 1967. 202p.

36. WALD, F.V. Investigation of copper-manganese-nickel alloys for dental purpose. J Dent Res, v.50, n.1, p.48-59, Jan./Feb. 1971.

37. WANG, R.R.; BOYLE, A. A simple method for inspection of porosity in titanium castings. J Prosthet Dent, v.70, n.3, p.275-276, Sept. 1993.

38. WANG, R.R.; FENTON, A. Titanium for prosthodontic applications: a review of the literature. Quintessence Int, v.27, n.6, p.401-408, June 1996.

39. WATAHA, J.C. Biocompatibility of dental casting alloys: a review. J Prosthet Dent, v.83, n.2, p.223-234, Feb. 2000.

40. WATAHA, J.C.; LOCKWOOD, P.E.; KHAJOTIA, S.S.; TURNER, R. Effect of $\mathrm{pH}$ on element release from dental casting alloys. $\mathbf{J}$ Prosthet Dent, v.80, n.6, p.691-698, Dec. 1998.

41. WIEGMAN-HO, L.; KETELAAR, J.A.A. Corrosion rate studies: measurements of corrosion rates of some non-precious dental alloys in artificial saliva. J Dent, v.15, n.4, p.166-170, Aug. 1987. 
42. WILLIAMS, D.F. Biocompatibility of Clinical Implant Materials. Boca Raton: CRC, 1984. p.44-46.

43. YOUSSEF, M.N. Polimento e repolimento de corpos de prova de ligas de cobre alumínio. Estudo rugosimétrico da superfície. São Paulo, 1995. 58p. Tese (Livre Docência em Dentística) - Faculdade de Odontologia da Universidade de São Paulo. 


\section{APÊNDICE}

Médias x corpo de prova utilizadas nas análises

\begin{tabular}{|c|c|c|c|}
\hline Liga & Fase I & Fase II & Fase III \\
\hline $\mathrm{Ti}$ & 0.302 & 0.334 & 0.328 \\
\hline $\mathrm{Ti}$ & 0.330 & 0.352 & 0.276 \\
\hline $\mathrm{Ti}$ & 0.360 & 0.414 & 0.482 \\
\hline $\mathrm{Ti}$ & 0.300 & 0.294 & 0.290 \\
\hline $\mathrm{Ti}$ & 0.338 & 0.344 & 0.466 \\
\hline $\mathrm{Ti}$ & 0.316 & 0.326 & 0.308 \\
\hline $\mathrm{Ti}$ & 0.332 & 0.352 & 0.466 \\
\hline $\mathrm{Ti}$ & 0.352 & 0.394 & 0.336 \\
\hline $\mathrm{Ti}$ & 0.336 & 0.370 & 0.574 \\
\hline $\mathrm{Ti}$ & 0.300 & 0.272 & 0.290 \\
\hline $\mathrm{Ti}$ & 0.378 & 0.386 & 0.386 \\
\hline $\mathrm{Ti}$ & 0.358 & 0.362 & 0.462 \\
\hline $\mathrm{Ti}$ & 0.328 & 0.564 & 0.416 \\
\hline $\mathrm{Ti}$ & 0.342 & 0.362 & 0.416 \\
\hline $\mathrm{Ti}$ & 0.334 & 0.356 & 0.382 \\
\hline $\mathrm{Ti}$ & 0.306 & 0.396 & 0.332 \\
\hline $\mathrm{Ti}$ & 0.418 & 0.320 & 0.378 \\
\hline $\mathrm{Ti}$ & 0.374 & 0.476 & 0.418 \\
\hline $\mathrm{Ni}-\mathrm{Cr}$ & 0.306 & 0.458 & 0.276 \\
\hline $\mathrm{Ni}-\mathrm{Cr}$ & 0.304 & 0.318 & 0.332 \\
\hline $\mathrm{Ni}-\mathrm{Cr}$ & 0.302 & 0.272 & 0.326 \\
\hline $\mathrm{Ni}-\mathrm{Cr}$ & 0.318 & 0.330 & 0.540 \\
\hline $\mathrm{Ni}-\mathrm{Cr}$ & 0.364 & 0.366 & 0.310 \\
\hline $\mathrm{Ni}-\mathrm{Cr}$ & 0.368 & 0.376 & 0.390 \\
\hline $\mathrm{Ni}-\mathrm{Cr}$ & 0.334 & 0.256 & 0.748 \\
\hline $\mathrm{Ni}-\mathrm{Cr}$ & 0.360 & 0.250 & 0.370 \\
\hline $\mathrm{Ni}-\mathrm{Cr}$ & 0.244 & 0.312 & 0.260 \\
\hline $\mathrm{Ni}-\mathrm{Cr}$ & 0.292 & 0.302 & 0.364 \\
\hline $\mathrm{Ni}-\mathrm{Cr}$ & 0.356 & 0.396 & 0.324 \\
\hline $\mathrm{Ni}-\mathrm{Cr}$ & 0.332 & 0.336 & 0.530 \\
\hline $\mathrm{Ni}-\mathrm{Cr}$ & 0.440 & 0.354 & 0.342 \\
\hline $\mathrm{Ni}-\mathrm{Cr}$ & 0.344 & 0.364 & 0.500 \\
\hline $\mathrm{Ni}-\mathrm{Cr}$ & 0.290 & 0.278 & 0.440 \\
\hline $\mathrm{Ni}-\mathrm{Cr}$ & 0.270 & 0.444 & 0.286 \\
\hline $\mathrm{Ni}-\mathrm{Cr}$ & 0.224 & 0.292 & 0.340 \\
\hline $\mathrm{Ni}-\mathrm{Cr}$ & 0.346 & 0.266 & 0.368 \\
\hline & & & \\
\hline
\end{tabular}




\section{SUMMARY}

\section{“IN VITRO” STUDY OF THE SURFACE SMOOTHNESS OF TWO KINDS OF ALLOYS - TITANIUM AND NICKEL - CHROMIUM, SUBMITTED TO THERMO CYCLING AT INTERVALS, THROUGH RUGOSIMETRY}

The resistance capacity to corrosion to which the dental prosthesis made in mettalic alloys are subject has a major importance in the dental clinic, due to the occurance of possible biological reactions such as, for example, allergic symptoms and degradation of restorations. As there are several factors acting in the oral medium, every restoration material, either metallic or not, is subject to a deterioration action in its surface, caused by $\mathrm{pH}$ variation, alimentary diet, temperature and chewing. New metallic alloys have been developed, among them the Titanium (Ti), which presents excellent acceptance in the dentistry area, mainly in the industry of dental implants. This study appraised the superficial rugosity of two metallic alloys Titanium e Nickel Chromium (Ni $\mathrm{Cr}$ ) in three different phases, through readings made by the surface rugosimeter in the test bodies, submitted to thermal cycling and submerged in artificial saliva at constant temperature of 37 degrees, for a period of 8 months. Through the achieved statistic results, it may be 
concluded that there is no difference between the alloys, concerning the time and visual aspect factors, there being a significant difference only between phases I and III of the study. 